\title{
Effect of Organic Montmorillonite on Properties of High-viscosity Modified Asphalt
}

\author{
Yongmei Guo*, Yadong JIE \\ College of Civil Science and Engineering, Yangzhou University, Yangzhou 225127, China
}

\begin{abstract}
In order to investigate the effect of organic montmorillonite (OMMT) and its content on properties of high-viscosity modified asphalt, a series of laboratory tests were carried out through zero shear viscosity (ZSV) at $60{ }^{\circ} \mathrm{C}$, rutting factor, ductility at $5{ }^{\circ} \mathrm{C}$, and fatigue factor to analyze hightemperature, low-temperature and anti-fatigue properties of high-viscosity modified asphalt with different OMMT contents. The results show that OMMT/high-viscosity modifier (HVM) composite modification can improve obviously high-temperature performance and fatigue resistance of high-viscosity modified asphalt, but the best improvement effect can be achieved only when adding proper amount of OMMT. The addition of a small amount of OMMT has little effect on low-temperature performance of high-viscosity modified asphalt, but when the content of OMMT exceeds $4 \%$, its low-temperature performance will decrease significantly. The addition of OMMT can improve the temperature sensitivity of high-viscosity modified asphalt's high-temperature performance, but reduces the temperature sensitivity of its fatigue resistance.
\end{abstract}

\section{Introduction}

Asphalt pavement is the main pavement form of highgrade highway in China. But as a pavement material, asphalt has many disadvantages, for example, it becomes soft and sticky at high temperature, and becomes brittle and cracked at low temperature, and may occur fatigue under repeated loading. Therefore, it has been a hot research field on how to improve the performance of asphalt pavement. Road engineers have found in their exploration that the use of modified asphalt binders is one of the most effective means. After adding modifiers such as rubber and resin into ordinary asphalt binders or asphalt mixtures, their high temperature anti-rutting, low temperature anti-cracking and anti-fatigue properties can be improved to some extent. But some studies also found that densities and molecular structures of most modifiers are different from those of asphalt binder, so their compatibility with matrix asphalt is poor, which makes properties of modified asphalt decrease [1].

Montmorillonite is a kind of nano-clay with layered silicate structure, which has the characteristics of high strength and large specific surface area. After organic treatment, it can form nano-composite structure with other modifiers, which can obviously improve the compatibility between matrix asphalt and modifier, and thus enhance properties of modified asphalt. Some researchers have discussed the improvement of various properties for styrene-butadiene-styrene (SBS), waste rubber powder, epoxy and octyl phthalate (DOP) modified asphalt binders by adding proper amount of organic Montmorillonite (OMMT) [2-5]. However, there are few studies on using OMMT to improve properties of high-viscosity modified asphalt. In this paper, highviscosity modified asphalt samples were prepared using the melt mixing method by adding OMMT and highviscosity modifier (HVM) into matrix asphalt. The influence of OMMT and its content on properties of high-viscosity modified asphalt was studied by analyzing high-temperature performance, low-temperature performance and fatigue resistance of high-viscosity modified asphalt with different OMMT contents how to change.

\section{Raw materials}

\subsection{Matrix asphalt}

The 70A grade matrix asphalt is produced by Taizhou Asphalt Products Co., Ltd. Its technical index according to the Chinese Technical Specifications for Construction of Highway Asphalt Pavements [6] is shown in table 1.

Table 1. Technical index of the 70A matrix asphalt.

\begin{tabular}{ccccc}
\hline $\begin{array}{c}\text { Penetration at } 25{ }^{\circ} \mathrm{C} \\
(0.1 \mathrm{~mm})\end{array}$ & $\begin{array}{c}\text { Softening point } \\
\left({ }^{\circ} \mathrm{C}\right)\end{array}$ & $\begin{array}{c}\text { Ductility at } 10{ }^{\circ} \mathrm{C} \\
(\mathrm{cm})\end{array}$ & $\begin{array}{c}\text { Dynamic viscosity } \\
\text { at } 60{ }^{\circ} \mathrm{C}(\mathrm{Pa} \cdot \mathrm{s})\end{array}$ & $\begin{array}{c}\text { Relative density } \\
\text { at } 15{ }^{\circ} \mathrm{C}\end{array}$ \\
\hline 64 & 48.5 & 115 & 234 & 1.011 \\
\hline
\end{tabular}

\footnotetext{
*Corresponding author's e-mail:gym_yz@163.com
} 


\subsection{High-viscosity modifier}

High-viscosity modifier is from Good Garden Commercial Joint-stock Corporation in Japan. It is a kind of yellow semitransparent particle with a volume weight of $0.6 \mathrm{t} / \mathrm{m}^{3}$.

\subsection{Organic montmorillonite}

Organic montmorillonite is produced by Zhejiang Fenghong New Material Co., Ltd., the largest particle size is $130 \mathrm{~nm}$, average particle size is $75 \mathrm{~nm}$, and the diameter thickness ratio is $>200$.

\section{Preparation of high-viscosity modified asphalt with different OMMT contents}

In this paper, high-speed shear emulsifier BME100LT was used in the preparation of high-viscosity modified asphalt with different OMMT contents. The preparation processes are as follows:

(1) The $70 \mathrm{~A}$ matrix asphalt was heated to $160{ }^{\circ} \mathrm{C}$ in the oven and was held for $1 \mathrm{~h}$, then $13 \%$ of HVM were added into the matrix asphalt; the mixture was stirred with a glass rod for $5 \mathrm{~min}$ and then high-speed sheared for $20 \mathrm{~min}$ at $2000 \mathrm{rpm}$ with BME100LT.

(2) Different contents $(0 \%, 1 \%, 2 \%, 3 \%, 4 \%$, and $5 \%$, resp.) of OMMT were added into the mixed asphalt; the mixture was rotated at $4500 \mathrm{rpm}$ for $60 \mathrm{~min}$. Temperature was controlled to $180{ }^{\circ} \mathrm{C}$ in the shearing process.

(3) The mixture was placed in the oven at $163{ }^{\circ} \mathrm{C}$ for $60 \mathrm{~min}$.

So, high-viscosity modified asphalt with different OMMT contents were prepared. The prepared samples were labeled separately and preserved in a thermostat oven at $180{ }^{\circ} \mathrm{C}$ for subsequent tests.

\section{The effect of OMMT on properties of high-viscosity modified asphalt}

\subsection{High-temperature performance}

High-viscosity modified asphalt is mainly used in porous asphalt pavement at present. In order to resist the damage caused by rain, it needs to have higher viscosity than ordinary modified asphalt. According to the Shanghai Technical Specifications for Drainage Asphalt Pavement of Road in China [7], Zero Shear viscosity (ZSV) of high-viscosity modified asphalt at $60{ }^{\circ} \mathrm{C}$ is required to be tested. This index can also reflect the high-temperature performance of asphalt binder. The ZSV values at $60{ }^{\circ} \mathrm{C}$ of high-viscosity modified asphalt with different OMMT contents were obtain as shown in figure 1 by using shear rate scanning test.

From figure 1, it can be seen that $\mathrm{ZSV}$ increases rapidly with the increasing of OMMT content at $60{ }^{\circ} \mathrm{C}$, and reaches its maximum value at the OMMT content of
$4 \%$, which is 1.4 times higher than that when OMMT is not added. This shows that OMMT/HVM composite modification can obviously improve high-temperature performance of high-viscosity modified asphalt. On the one hand, it may indicates that OMMT is dispersed in high-viscosity modified asphalt by high-speed shearing to form a kind of intercalated or exfoliated nano-layered structure, which can restrict the molecular chain movement of HVM and matrix asphalt. With the increase of the OMMT content, the thickness of layered structure is increasing, which makes the confinement stronger. On the other hand, the addition of OMMT can reduce the average particle size of HVM in matrix asphalt, which not only improves the uniformity of HVM particle distribution, but also increases its specific surface area, thus enhancing the interfacial contact friction between matrix asphalt and HVM. Therefore, the viscosity of high-viscosity modified asphalt increases greatly after adding OMMT. However, as can be seen from figure 1 , when the content of OMMT exceeds $4 \%$, ZSV at $60{ }^{\circ} \mathrm{C}$ begins to decline, which indicates that the amount of OMMT should be appropriate.

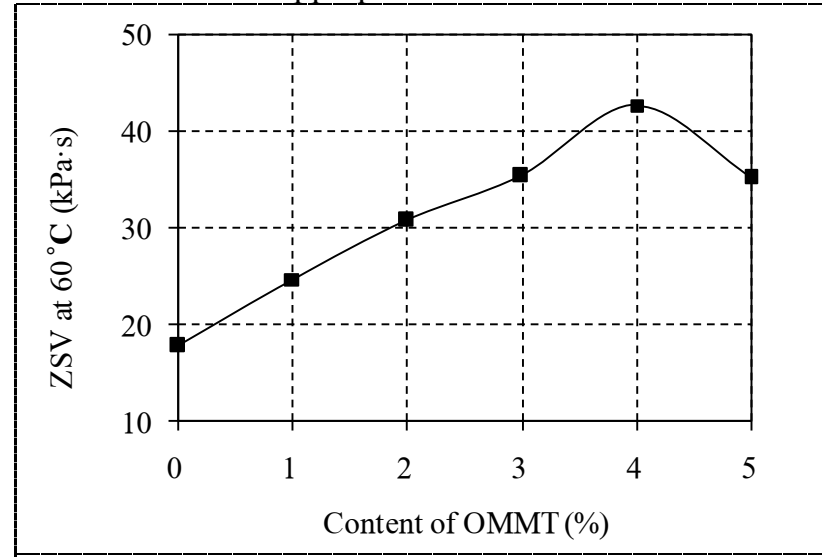

Figure 1. Variation of ZSV at $60{ }^{\circ} \mathrm{C}$ with OMMT content.

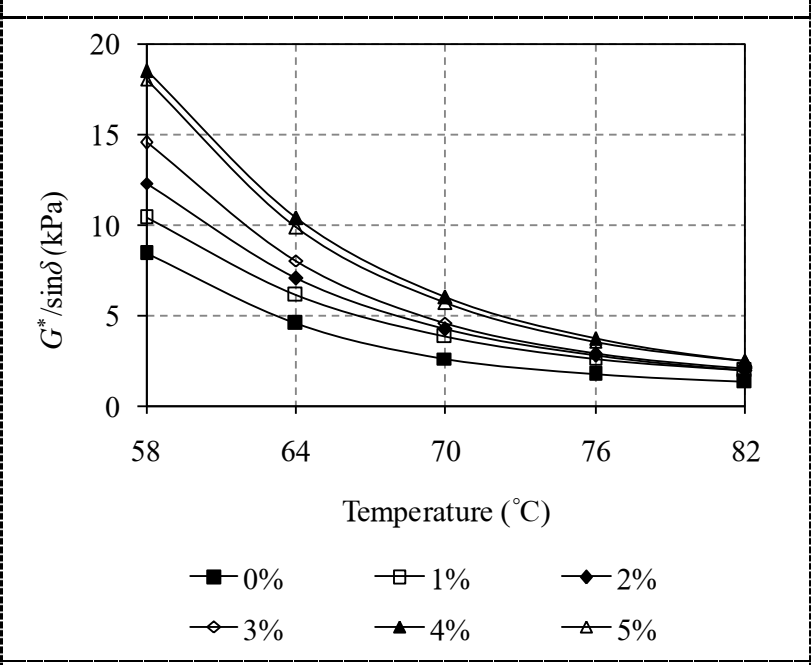

Figure 2. Variation of $G^{*} / \sin \delta$ with temperature at different OMMT contents.

Dynamic Shear rheological (DSR) tests were also used to evaluate the high-temperature performance of high-viscosity modified asphalt with different OMMT contents. DSR tests were conducted at different 
temperatures $\left(58{ }^{\circ} \mathrm{C}, 64{ }^{\circ} \mathrm{C}, 70{ }^{\circ} \mathrm{C}, 76{ }^{\circ} \mathrm{C}\right.$, and $\left.82{ }^{\circ} \mathrm{C}\right)$. The influence of OMMT and its content on the rutting factor $G^{*} / \sin \delta$ of different high-viscosity modified asphalt binders was obtained as shown in figure 2 .

From figure 2, it can be seen that

(1) With the increase of temperature, the rutting factor, $G^{*} / \sin \delta$ decreases gradually, which shows that the higher the temperature is, the worse the rutting resistance is. This is consistent with the change law of hightemperature performance of asphalt pavement in summer.

(2) With the addition of OMMT, the Slope of $G^{*} / \sin \delta$ and temperature relation curve increases, especially between $54{ }^{\circ} \mathrm{C}$ and $64{ }^{\circ} \mathrm{C}$, which indicates that the temperature sensitivity of high-viscosity modified asphalt's rutting resistance increases.

(3) At the same temperature, the change of $G^{*} / \sin \delta$ is similar to that of ZSV at $60{ }^{\circ} \mathrm{C}$, and it shows that the first increases and then decreases with the increase of OMMT content, and both reach the peak values when the content of OMMT is $4 \%$. The result shows that adding proper amount of OMMT could improve the high-temperature performance of high-viscosity modified asphalt. This may be due to the fact that when the content of OMMT exceeds a certain range, the aggregation of OMMT becomes prominent and it can not be uniformly dispersed in high-viscosity modified asphalt, thus affecting the performance improvement at high temperature.

\subsection{Low-temperature performance}

Ductility at $5{ }^{\circ} \mathrm{C}$ test was carried out on high-viscosity modified asphalt with different OMMT contents according to the Chinese test specification [8]. The influence of OMMT and its content on the lowtemperature performance of high-viscosity modified asphalt was obtained as shown in figure 3 . As can be seen from figure 3, when the content of OMMT is low, ductility at $5{ }^{\circ} \mathrm{C}$ increases, but the amplitude is small. When the content of OMMT increases gradually, ductility at $5{ }^{\circ} \mathrm{C}$ begins to decrease after the content of OMMT exceeds $3 \%$. This shows that the addition of a small amount of OMMT has little effect on the lowtemperature performance of high-viscosity modified asphalt, but the addition of more than $4 \%$ will obviously reduce its low-temperature performance.

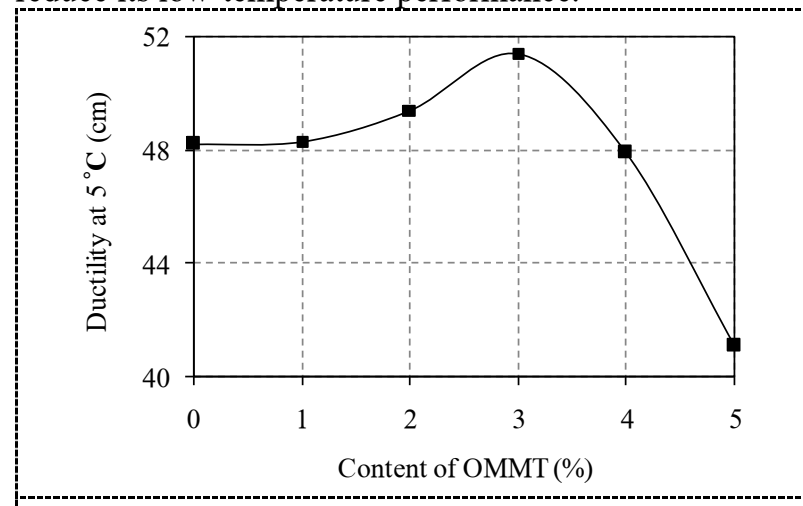

Figure 3. Variation of ductility at $5{ }^{\circ} \mathrm{C}$ with OMMT content.

\subsection{Fatigue resistance}

DSR tests were carried out at different temperatures $\left(15{ }^{\circ} \mathrm{C}, 18{ }^{\circ} \mathrm{C}, 21{ }^{\circ} \mathrm{C}, 24{ }^{\circ} \mathrm{C}\right.$, and $\left.27{ }^{\circ} \mathrm{C}\right)$ on high-viscosity modified asphalt with different OMMT contents. The influence of OMMT and its content on the fatigue factor $G^{*} \cdot \sin \delta$ of different high-viscosity modified asphalt binders was obtained as shown in figure 4.

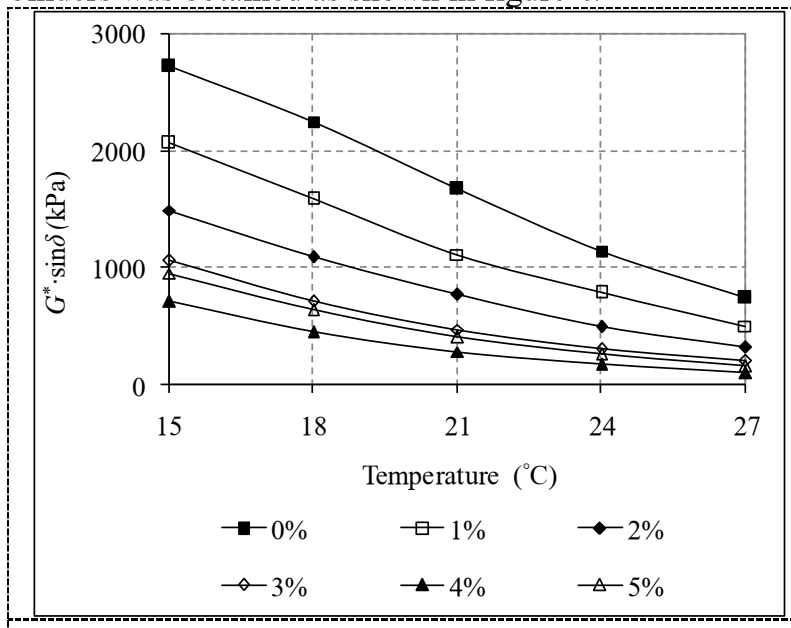

Figure 4. Variation of $G^{*} \cdot \sin \delta$ with temperature at different OMMT contents.

From figure 4, it can be seen that

(1) With the increase of temperature, the fatigue factor, $G^{*} \cdot \sin \delta$ decreases gradually, which shows that the higher the temperature is, the better the fatigue resistance is. This is accords with the rheological property general law of asphalt binder.

(2) After adding OMMT, the slope of $G^{*} \cdot \sin \delta$ and temperature relation curve decreases, especially when the content of OMMT is $4 \%$, which indicates that the temperature sensitivity of fatigue resistance of highviscosity modified asphalt increases.

(3) At the same temperature, with the increase of the content of OMMT, $G^{*} \cdot \sin \delta$ decreases gradually at first, which reaches the minimum value when the content of OMMT is $4 \%$. And then, when the content of OMMT increases, $G^{*} \cdot \sin \delta$ also increases, but it is still much smaller than when OMMT is not added. The result shows that the modulus loss of high-viscosity modified asphalt under dynamic loading decreases obviously by adding proper content of OMMT, and its fatigue resistance increases greatly.

\section{Conclusions}

In this paper, high-viscosity modified asphalt samples with different OMMT contents were prepared. Their properties were tested through the ZSV, rutting factor, ductility, and fatigue factor. So, the effect of OMMT and its content on properties of high-viscosity modified asphalt was analyzed according to the test results.

(1) OMMT/HVM composite modification can improve obviously high-temperature performance and fatigue resistance of high-viscosity modified asphalt, but 
the best improvement effect can be achieved only when adding proper amount of OMMT.

(2) The addition of a small amount of OMMT has little effect on low-temperature performance of highviscosity modified asphalt, but when the content of OMMT exceeds $4 \%$, its low-temperature performance will decrease significantly.

(3) The addition of OMMT can improve the temperature sensitivity of high-viscosity modified asphalt's high-temperature performance, but reduces the temperature sensitivity of its fatigue resistance.

\section{Acknowledgments}

This work is supported by Jiangsu Province Construction System of China (2017ZD101) and the Science and Innovation Project of Yangzhou University Student of China (X20190452).

\section{References}

1. Sun, D., Lu, W. (2003) Investigation and improvement of storage stability of SBS modified asphalt. Petroleum Science and Technology, 21: 901-910.

2. Zhang, H., Zhu, C., Tan, B., Shi, C. (2014) Effect of organic layered silicate on microstructures and aging properties of styrene-butadiene-styrene copolymer modified bitumen. Construction and Building Materials, 68: 31-38.

3. Tan, B. (2018) Study on rheological properties of organic montmorillonite- rubber composite modified asphalt. Hunan Communication Science and Technology, 44: 99-101.

4. Xiao, X., Zhang, D., Yan, Y., Zhu W. (2015) Properties of asphalt modified with organic montmorillonite/epoxy resin. Journal of South China University of Technology (Natural Science Edition), 43: 139-143.

5. Liu, Q., Yin, Y., Zeng, D. (2016) The preparation and properties of montmorillonite/DOP modified asphalt. Journal of Changsha University of Science and Technology (Natural Science Edition), 13: 6-11.

6. JTG F40-2004. Technical Specifications for Construction of Highway Asphalt Pavements, China Communications Press, Beijing.

7. DG/TJ 08-2074-2016. Technical Specifications for Drainage Asphalt Pavement of Road, Tongji University Press, Shanghai.

8. JTG E20-2011. Standard Test Methods of Bitumen and Bituminus Mixture for Highway Engineering, China Communications Press, Beijing. 